\title{
ESTUDO DA REMOÇÃO DE INIBIDORES DE FERMENTAÇÃO APÓS TRATAMENTO ÁCIDO E ENZIMÁTICO DE PALHA DE CANA
}

\author{
A. C. LUCARINI ${ }^{1, *}$, N. L. FERREIRA ${ }^{1}$, C. D. SOUZA ${ }^{1}$, F. P. L. FRANCISCO ${ }^{1}$, \\ I. R. FONSECA ${ }^{1}$, L. G. ROSSI ${ }^{1}$ e V. M. FERREIRA ${ }^{1}$ \\ ${ }^{1}$ Centro Universitário FEI, Departamento de Engenharia Química \\ *E-mail: lucarini@fei.edu.br
}

\begin{abstract}
RESUMO: Neste trabalho estudou-se a remoção do furfural, inibidor tóxico à fermentação, formado no pré-tratamento ácido de lignocelulósicos. Experimentalmente estudaram-se no pré-tratamento diferentes concentrações de $\mathrm{H}_{2} \mathrm{SO}_{4}(1 \%, 2,5 \%$ e 5\%) e tempos de reação (15, 30 e 60 minutos). Definiu-se como condição mais adequada $1 \% \mathrm{~m} / \mathrm{m}$ de ácido sulfúrico e 15 minutos como tempo de reação. Com os dados experimentais realizou-se a simulação da remoção do furfural e da concentração dos açúcares. As correntes contendo açúcares foram denominadas de C5 (hidrolisado ácido - xilose e furfural) e C6 (hidrolisado enzimático glicose). A corrente C5 foi purificada e concentrada através de uma coluna de enchimento integrada a evaporadores múltiplos com cinco efeitos, com gasto energético de 0,85 kW/kg de xilose. Para concentrar a corrente C6 de 14 a 20\% de açúcares utilizaram-se evaporadores múltiplos com quatro efeitos com gasto energético requerido de 0,34 $\mathrm{kW} / \mathrm{kg}$ de glicose.
\end{abstract}

PALAVRAS-CHAVE: Etanol. Furfural. Lignocelulósicos. Pré-tratamento ácido. Biomassa.

\section{INTRODUÇÃO}

Atualmente um dos principais focos de pesquisas em engenharia visa a substituição dos combustíveis fósseis. O uso de biocombustíveis produzidos a partir de biomassa vem ganhando bastante força, pois estes permitem a diminuição do uso de recursos não renováveis e a redução da emissão de gases que provocam o efeito estufa. $\mathrm{O}$ etanol é um exemplo de fonte de energia renovável, pois trata-se de um biocombustível que pode ser obtido de diversas fontes renováveis, e, dependendo de sua origem, pode ser classificado nas categorias de etanol de primeira ou segunda geração. Etanol de primeira geração refere-se ao etanol produzido a partir de fontes agrícolas primárias, geralmente matérias-primas sacaríneas, como a cana-de-açúcar, ou amiláceas, como o milho e a mandioca. $\mathrm{O}$ de segunda geração é produzido a partir da biomassa lignocelulósica. A utilização de materiais lignocelulósicos para produção de etanol no Brasil vem ganhando cada vez mais destaque em pesquisas, para viabilizar sua utilização, uma vez que o Brasil é responsável por uma das maiores produções mundiais de cana-de-açúcar (NOVACANA, 2013). 


\subsection{Biomassa Lignocelulósica}

O termo biomassa lignocelulósica refere-se a materiais de origem vegetal e/ou microbiana compostos por celulose, lignina e hemicelulose, e representam metade da biomassa do planeta. Resíduos agrícolas, como palhas, bagaços, sabugos e/ou restos das fontes agrícolas são exemplos de biomassa lignocelulósica. Este tipo de material também é utilizado na produção de energia, na fabricação de ração animal, entre outros processos, mas muitas vezes não é levado em consideração seu potencial energético e é descartado ao ambiente (SANTOS et al., 2012).

A utilização de resíduos agrícolas tais como a palha de cana, como matéria-prima para produção de etanol de segunda geração, mostra-se interessante já que, nos próximos anos, haverá um aumento na sua disponibilidade com o fim das queimadas na colheita de cana-deaçúcar (SANTOS et al., 2012). A utilização da palha e do bagaço da cana possibilitará dobrar a produção de etanol em uma unidade de produção, sem ter que aumentar o tamanho da área cultivada, o que gera menor impacto ambiental, permite também a produção do biocombustível mesmo na entressafra da cana e a diminuição de emissão de carbono durante a produção (RAÍZEN, 2014). A utilização de materiais lignocelulósicos para produção de etanol no Brasil vem ganhando cada vez mais destaque em pesquisas para viabilizar sua utilização, uma vez que o Brasil é responsável por uma das maiores produções mundiais de cana-de-açúcar. Além disso, estudos apontam que o potencial energético da cana se divide igualmente em: caldo, bagaço e palha, onde cada parte representa $1 / 3$ da energia total (SANTOS et al., 2012).

Os teores de celulose, lignina e hemicelulose presentes na biomassa lignocelulósica variam conforme o tipo matéria-prima. A celulose é o principal componente da composição química da biomassa lignocelulósica e também o principal alvo da bioconversão. A composição de celulose no material lignocelulósico geralmente varia de 35 a 50\% e depende do tipo de biomassa (SANTOS et al., 2012). A celulose é formada por ligações do tipo $\beta-1,4-$ glicosídicas e é considerada um homopolissacarídeo constituído por milhares de moléculas de D-glicose, formando uma longa cadeia linear, com forte tendência a realizar ligações de hidrogênio intramoleculares e intermoleculares (SJÖSTRÖM, 1993). Por causa das interações de hidrogênio intramoleculares, a celulose possui uma estrutura rígida, enquanto que as interações de hidrogênio entre as macromoléculas vizinhas conferem elevada insolubilidade em água (GUHA et al., 2010). As macromoléculas de celulose ao se agregarem formam regiões mais organizadas (cristalinas) alternadas por regiões menos organizadas (amorfas), além de estarem envolvidas por uma matriz amorfa de polissacarídeos não celulósicos, que dificultam a ação de micro-organismos e enzimas na conversão do material celulósico em glicose (SANTOS et al., 2012).

A hemicelulose é um polissacarídeo complexo e um dos componentes que envolve as fibras de celulose na matriz amorfa do material lignocelulósico. Diferentemente da celulose, a hemicelulose é um heteropolissacarídeo constituído por diferentes moléculas de açúcares de 5 e 6 carbonos, incluindo pentoses (xilose, raminose e arabinose), hexoses (glicose, galactose e manose) e ácidos urônicos (RAMOS, 2003). Estruturalmente mais semelhante à celulose do que à lignina, a hemicelulose possui uma cadeia ramificada com cadeias laterais que interagem com a celulose conferindo estabilidade ao conjunto (RAMOS, 2003). Em 
contraste com a celulose, a hemicelulose possui facilidade de sofrer hidrólise em meio ácido, uma vez que os ácidos possuem maior acesso à macromolécula devido à sua estrutura amorfa (SANTOS et al., 2012).

Formada por três blocos de construção (álcool p-cumarílico, o álcool coferílico e o álcool sinapílico), a lignina é uma macromolécula amorfa que possui uma estrutura fenólica complexa. Combinada com a hemicelulose nas paredes celulares dos vegetais, forma uma matriz amorfa não celulósica em torno da celulose atuando como uma barreira física evitando que as enzimas de micro-organismos quebrem as macromoléculas de celulose em glicose (SANTOS et al., 2012).

\subsection{Pré-tratamento da Biomassa}

O processo de produção do etanol de segunda geração consiste em várias etapas, sendo as duas principais: o pré-tratamento e a sacarificação da biomassa. O processo de prétratamento da biomassa é responsável pela modificação ou remoção das ligações entre a lignina, a celulose e a hemicelulose, o que leva à redução da cristalinidade da celulose (GROSSI, 2015), facilitando a quebra das macromoléculas de celulose em glicose na sacarificação (SANTOS et al., 2012).

Existem diversos tipos de pré-tratamento, com diferentes efeitos e rendimentos, e que interferem de maneira diferente em etapas subsequentes. Os tipos de pré-tratamento, podem ser divididos em diferentes grupos: físicos (moagem e trituração), químicos (ácido diluído, agentes oxidantes, alcalino, e solventes orgânicos), físico-químicos (hidrotérmicos, prétratamento a vapor e oxidação úmida), biológicos (uso de enzimas e fungos) e a combinação destes (OLIVEIRA, 2010).

Pré-tratamento com ácido diluído: O pré-tratamento com ácido diluído tem como característica aumentar a reatividade da celulose para a hidrólise enzimática. Este tipo de prétratamento é usado para promover a hidrólise da hemicelulose. Após o tratamento, é obtida uma solução hidrolisada que contem açúcares simples (glicose, galactose, arabinose e xilose) e um resíduo sólido formado por lignina e celulose (SILVA, 2009). O ácido sulfúrico é o mais utilizado, podendo ser também empregado outros ácidos, como por exemplo, os ácidos clorídrico e fosfórico. São utilizadas concentrações de ácido inferiores a $5 \%(\mathrm{~m} / \mathrm{m})$ e temperaturas elevadas, acima de $150{ }^{\circ} \mathrm{C}$. Aden et al (2002) descreve as condições operacionais ideais para hidrólise de palha de milho: $\mathrm{H} 2 \mathrm{SO} 41,1 \%(\mathrm{~m} / \mathrm{m}) ; 2$ minutos de reação; $190{ }^{\circ} \mathrm{C} ; 12,1$ atm e $30 \%$ de sólidos no reator de pré-tratamento.

A principal consequência deste pré-tratamento é a formação de uma série de compostos, sendo os principais: xilose, glicose, arabinose, ácido acético, o furfural e o 5hidroxi-metil-furfural (HMF), devido à quebra das ligações entre os açúcares monoméricos e as cadeias poliméricas da hemicelulose e da celulose (GONÇALVES, 2009). O principal inconveniente, além de ser um tratamento que requer equipamentos que resistam à corrosão, é a formação de inibidores de fermentação, compostos tóxicos tais como os aldeídos furfural e HMF, que inibem a maioria dos microrganismos produtores de etanol (RASMUSSEN et al., 2014).

Rasmussen et al. (2014) comparam os rendimentos da produção de etanol em presença 
dos inibidores. Para o furfural o rendimento cai de 8 a $50 \%$ nas concentrações de 21 a $65 \mathrm{mM}$; para o HMF, o rendimento cai cerca de 50\% nas faixas de concentração de 8 a 57 mM. Já para ácidos como levulínico, acético e fórmico, em concentrações maiores que 100 $\mathrm{mM}$ o rendimento diminui.

O furfural e o HMF são produtos primários da degradação dos carboidratos da biomassa lignocelulósica. O HMF é gerado a partir da degradação de hexoses, principalmente a glicose, através de um mecanismo bastante complexo com diversas vias reacionais. $\mathrm{O}$ furfural é obtido pela quebra das pentoses, xilose e arabinose, produtos obtidos da hidrólise da hemicelulose. Os dois aldeídos têm efeito negativo na taxa específica de crescimento de leveduras, na produção volumétrica e na produção específica de etanol, sendo o HMF um inibidor menos severo que o furfural (ZAUTSEN, 2011).

Para promover o aumento do rendimento da produção de etanol lignocelulósico é preciso que haja pesquisas que indiquem a melhor condição de remoção desses inibidores, uma etapa importante para a produção mais eficiente de etanol de segunda geração. O desafio da remoção desses agentes tóxicos inspirou a proposta do presente trabalho, que objetivou o estudo da remoção dos inibidores de fermentação, após pré-tratamento ácido da palha de cana-de-açúcar previamente deslignificada, e o estudo da concentração dos açúcares (xilose e glicose) presentes nos hidrolisados ácido e enzimático da biomassa.

Neste trabalho estudou-se o pré-tratamento ácido e hidrólise enzimática da palha de cana de açúcar e a remoção dos inibidores formados e concentração dos açúcares, para a produção de etanol de segunda geração.

\section{METODOLOGIA}

Este trabalho foi realizado em duas etapas: na primeira etapa foi realizado um estudo experimental de caracterização dos produtos obtidos após pré-tratamento ácido e hidrólise enzimática da biomassa estudada; e, na segunda etapa foi realizado um estudo por simulação da remoção dos inibidores e concentração dos açúcares, com base nos resultados obtidos experimentalmente.

\subsection{Parte Experimental}

Neste trabalho, utilizou-se como matéria-prima a palha de cana-de-açúcar, previamente moída e deslignificada com peróxido de hidrogênio (2\%) em meio alcalino (AZZAM, 1989). Após a secagem do material, esta biomassa passou pelas etapas de pré-tratamento com ácido sulfúrico diluído, hidrólise enzimática e caracterização.

Pré-tratamento com ácido diluído: Para definir a condição a ser empregada no prétratamento ácido, testaram-se as concentrações de ácido sulfúrico 1\%, 2,5\% e 5\% (m/m). Após esse estudo, seguiu-se para os testes com os tempos de reação: 15, 30 e 60 minutos. Para o estudo da concentração de ácido estipulou-se o tempo fixo de 60 minutos e após a decisão em relação à concentração, manteve-se esta variável constante e variou-se o tempo. No pré-tratamento ácido, utilizaram-se 30 gramas de biomassa e 1 litro de solução ácida (3\% de sólidos). A reação ocorreu em uma autoclave, com uma temperatura de $127^{\circ} \mathrm{C}$ e pressão máxima de 1,5 atm de operação. Ao término do pré-tratamento, as amostras seguiram para 
filtração, obtendo-se a polpa e o hidrolisado ácido. A polpa foi lavada até neutralização completa. A polpa neutralizada foi seca e seguiu para os testes de teores de lignina, holocelulose, celulose e cinzas. O filtrado foi analisado quanto aos teores de açúcares redutores, glicose, furfural e 5-hidroxi-metil-furfural.

Hidrólise Enzimática: Neste trabalho foi utilizado uma mistura de duas celulases comerciais, a CellicCTec2® e a CellicHTec2® cedidas pela Novozymes Brasil. O valor de atividade definido foi de $10 \mathrm{FPU} / \mathrm{g}$ de biomassa de cada enzima, sendo que $1 \mathrm{FPU}$ corresponde à uma unidade de papel de filtro (filter paper unit), como descrito por Ghose (1987). Realizou-se a hidrólise enzimática nas biomassas obtidas nos tempos de reação estudados no pré-tratamento: 15, 30 e 60 minutos. A hidrólise foi conduzida da seguinte forma: em um erlenmeyer, adicionou-se à biomassa um volume de solução contendo as enzimas (solução tampão citrato $0,05 \mathrm{~mol} / \mathrm{L} \mathrm{pH} \quad 4,8$ contendo 2,76 $\mathrm{g} / \mathrm{L}$ da enzima CellicCTec2 e 4,22 g/L da enzima CellicHTec2), adequado para manter $1 \%$ de sólidos na mistura. A mistura foi levada ao agitador orbital onde permaneceu por 48 horas a uma temperatura de $45^{\circ} \mathrm{C}$ e rotação de $150 \mathrm{rpm}$. Ao término da hidrólise, filtrou-se a mistura, a parte sólida foi levada à estufa por 24 horas, a $90^{\circ} \mathrm{C}$ e o filtrado foi armazenado para análise espectrofotométrica dos teores de açúcares redutores e glicose.

\subsection{Determinações Analíticas}

Determinação do teor de lignina Klason: Para este teste, adicionou-se $20 \mathrm{~mL}$ de $\mathrm{H}_{2} \mathrm{SO}_{4}$ $72 \%(\mathrm{~m} / \mathrm{m})$ em $1 \mathrm{~g}$ de biomassa. A mistura foi agitada por 2 horas a uma agitação de $200 \mathrm{rpm}$ e temperatura ambiente. Adicionou-se $560 \mathrm{~mL}$ de água destilada e a mistura seguiu para um refluxo de 4 horas. Após o refluxo, o material seguiu para uma filtração a vácuo em placa de vidro sinterizada, previamente seca e tarada, onde o resíduo foi lavado com água destilada até $\mathrm{pH}$ neutro. Transferiu-se o resíduo para estufa a $90^{\circ} \mathrm{C}$ até que se atingisse massa constante. Este ensaio foi baseado na norma TAPPI T222 om-02 (TAPPI, 2002).

Determinação do teor de holocelulose: Para este teste, pesou-se 3,5 g da biomassa, adicionaram-se $100 \mathrm{~mL}$ de água, 0,5 g de ácido acético glacial e 0,75 g de hipoclorito de sódio. Essa mistura foi levada a um banho a $70^{\circ} \mathrm{C}$, onde se manteve agitação constante. Após 1 hora de reação voltou-se a adicionar ácido acético glacial e hipoclorito de sódio repetindo o procedimento até completar 3 horas de reação. Resfriou-se a solução até $10^{\circ} \mathrm{C}$ e foi feita uma filtração em placa sinterizada. Transferiu-se o resíduo neutralizado para estufa a $90^{\circ} \mathrm{C}$ até que se atingisse massa constante. Este ensaio foi baseado na norma TAPPI Useful Method 249-75 (MORAIS et al., 2010).

Determinação do teor de celulose: Para a determinação do teor de celulose utilizou-se o resíduo sólido resultante do teste de teor de holocelulose como material de partida. Coletouse $1 \mathrm{~g}$ de amostra, adicionou-se $15 \mathrm{~mL}$ de hidróxido de potássio $24 \%(\mathrm{~m} / \mathrm{m})$. A mistura permaneceu sob agitação a $200 \mathrm{rpm}$ e temperatura ambiente por 24 horas. Realizou-se uma filtração em placa sinterizada, com lavagem do resíduo até atingir $\mathrm{pH}$ neutro, em seguida, lavou-se duas vezes com $50 \mathrm{~mL}$ de ácido acético $1 \%(\mathrm{~m} / \mathrm{m})$, e após, com etanol comercial em excesso. A amostra foi levada para estufa a $90^{\circ}$, onde permaneceu até atingir-se massa constante. Este ensaio foi baseado na norma TAPPI T203 cm-99 (MORAIS et al., 2010). 
Determinação da Concentração de Açúcares Redutores Totais: O procedimento de determinação da concentração de açúcares redutores baseou-se no método do reativo de DNS adaptado de Miller (1959). Adicionou-se $1 \mathrm{~mL}$ da amostra e 1,5 mL de solução do reativo DNS (ácido dinitrosalicílico) em um tubo de ensaio de $25 \mathrm{~mL}$. Aqueceu-se a mistura durante 5 minutos em um banho de água fervente. Resfriou-se a mistura e adicionou-se água destilada à mistura até completar $25 \mathrm{~mL}$. A determinação da absorvância foi realizada em um comprimento de onda de $540 \mathrm{~nm}$. Para a determinação da concentração de açúcares dos hidrolisados construiu-se uma curva de calibração em glicose com padrões de 0,1 a 1,0 g/L.

Determinação da concentração de glicose: Para a realização do teste, adicionou-se 50 $\mu \mathrm{L}$ da amostra em $5 \mathrm{~mL}$ do reativo enzimático LABTEST Glicose Liquiform ${ }^{\circledR}$ (Ref.: 133). A mistura foi levada a um banho termostatizado a $37^{\circ} \mathrm{C}$, onde permaneceu por 10 minutos. Realizou-se a leitura das absorvâncias em um comprimento de onda de $505 \mathrm{~nm}$. Para a determinação da concentração de açúcares dos hidrolisados construiu-se uma curva de calibração em glicose com padrões de 0,1 a $1,0 \mathrm{~g} / \mathrm{L}$.

Determinação da concentração de inibidores: O procedimento de determinação do teor dos inibidores furfural e 5-hidroximetilfutfural (HMF), foi realizado utilizando-se a técnica de cromatografia líquida de alta eficiência - HPLC. Utilizou-se um detector ultravioleta $(\lambda=254 \mathrm{~nm}$ ), fluxo de $0,8 \mathrm{~mL} / \mathrm{min}$; fase móvel com $80 \%$ de água e $20 \%$ acetonitrila e coluna C18. Para a determinação da concentração de HMF e Furfural presente nas amostras, construiu-se uma curva de calibração dos padrões destas substâncias.

\subsection{Simulação}

O estudo das operações unitárias para a remoção do furfural e concentração dos açúcares dos hidrolisados obtidos foi realizado através de simulação com auxílio do software ASPENPLUS®, baseando-se nos dados coletados experimentalmente.

Após a etapa experimental, realizou-se o balanço de massa para conhecer as composições das correntes dos hidrolisados e assim alimentar o simulador com os dados de entrada requeridos pelo software. Assim, têm-se duas correntes que foram tratadas via simulação, sendo a primeira corrente proveniente da hidrólise ácida (rica em pentoses e inibidores - corrente C5) e a segunda corrente oriunda da hidrólise enzimática (rica em hexoses - corrente C6). A corrente C5 contém açúcares de cinco carbonos, água e furfural. Supõe-se, portanto, que só há esses três componentes na corrente e todos os açúcares de cinco carbonos foram modelados como xilose. A corrente C6 contém predominantemente açúcares de seis carbonos e água, os quais foram modelados como glicose.

Para a construção da simulação neste trabalho, foi preciso selecionar o modelo termodinâmico que mais se adequava ao comportamento do sistema. Com o objetivo de obter os dados de equilíbrio, utilizou-se o NIST ThermoData Engine (TDE), um banco de dados disponível no ASPENPLUS ${ }^{\circledR}$ para correlacionar, estimar e predizer dados termodinâmicos. Após a adição dos componentes e da escolha do modelo termodinâmico, os blocos correspondentes às operações unitárias foram inseridos no ambiente de simulação. 
Para simular a remoção de furfural e concentração da corrente C5, estudaram-se três situações distintas: flash, coluna de destilação e coluna de destilação integrada a evaporadores de múltiplos efeitos. A simulação com o flash teve como especificações necessárias a pressão de operação (1 atm), vazão e temperatura da corrente de alimentação $\left(18373,92 \mathrm{~kg} / \mathrm{dia}\right.$ e $100,1^{\circ} \mathrm{C}$ respectivamente). Para a simulação com uma coluna de destilação fixaram-se as condições operacionais descritas na Tabela 1.

Tabela 1 - Dados fixos para simulação da remoção de furfural e concentração da corrente C5.

\begin{tabular}{cccccc}
\hline $\begin{array}{c}\text { Pressão de } \\
\text { operaçã̃o (atm) }\end{array}$ & $\begin{array}{c}\text { Vazão de } \\
\text { alimentação } \\
(\mathbf{k g} / \text { dia) }\end{array}$ & $\begin{array}{c}\text { Temperatura da } \\
\text { alimentação }\left({ }^{\circ} \mathbf{C}\right)\end{array}$ & Condensador & $\begin{array}{c}\text { Prato de } \\
\text { alimentação }\end{array}$ & $\begin{array}{c}\text { Razão de } \\
\text { refluxo }\end{array}$ \\
\hline 1,00 & 18373,92 & 100,10 & Total & 5 & 1,00 \\
\hline
\end{tabular}

Inicialmente fixou-se o número de pratos em 10 e variou-se a vazão de destilado de modo a atender as condições requeridas de remoção de furfural e concentração de açúcares na corrente final. $O$ valor inicial utilizado para o estudo da influência da vazão de destilado foi de $2500 \mathrm{~kg} /$ dia de destilado. Após definir a condição mais adequada de vazão de destilado, variou-se o número de pratos. Iniciou-se com número de pratos igual a 10 e por este motivo o prato de alimentação foi definido como 5 (metade da coluna). Ao longo do estudo com variações com relação ao número de pratos, optou-se por manter fixo este valor. Com os valores de número de pratos e vazão de destilado definidos, seguiu-se para a avaliação da faixa de concentração de açúcares na corrente final, com o intuiu de se atingir um melhor gasto energético. Os valores de concentração de açúcares para a corrente que alimenta a etapa de fermentação devem estar entre 14\% a 20\% (LIMA et al., 2001).

Para simular o uso de uma coluna de destilação integrada a evaporadores de múltiplos efeitos (5) mantiveram-se fixas as mesmas condições descritas na Tabela 1. Para iniciar a avaliação sobre as condições operacionais que foram aplicadas na destilação optou-se por fixar, primeiramente, a vazão do destilado em $2500 \mathrm{~kg} /$ dia e a concentração final de açúcares de corrente $\mathrm{C} 5$ que sai do evaporador em 18\%. A partir disto, avaliou-se o número de pratos que suprisse o objetivo de remover completamente os inibidores. Após analisar a influência do número de pratos sobre o percentual de inibidores na corrente final (condensado) e definir a condição mais adequada, optou-se por variar a vazão de destilado afim de se atingir menor gasto energético, mas garantindo a remoção máxima possível de furfural.

Com os valores de número de pratos e vazão de destilado definidos, seguiu-se para a avaliação da faixa de concentração de açúcares na corrente final. Os valores de concentração de açúcares para a corrente que alimenta a etapa de fermentação devem estar entre $14 \%$ a $20 \%$. A operação de evaporação foi realizada por cinco evaporadores em série com alimentação frontal, isto é, a solução diluída e o vapor fluem na mesma direção. A pressão de cada evaporador decresce conforme as correntes percorrem o conjunto de evaporadores (Tabela 2), de forma que a transferência de um efeito para outro é realizada sem a presença de bombas.

A concentração dos açúcares da corrente C6 foi estudada aplicando-se evaporadores de múltiplos efeitos, com 4 estágios. A pressão de cada estágio seguiu as mesmas condições aplicadas na corrente C5, até o quarto estágio (EVAP-4), descrito na Tabela 2.Variou-se a 
concentração da corrente final entre $14 \%$ a $20 \%$ de açúcares, faixa adequada para mostos de fermentação.

Tabela 2 - Condições fixadas nos evaporadores para a concentração dos açúcares.

\begin{tabular}{cccccc}
\hline $\begin{array}{c}\text { Pressão vapor de } \\
\text { aquecimento } \\
\left(\mathbf{k g f} / \mathbf{c m}^{2}\right)\end{array}$ & $\begin{array}{c}\text { Pressão } \\
\text { EVAP-1 } \\
(\text { atm })\end{array}$ & $\begin{array}{c}\text { Pressão } \\
\text { EVAP-2 } \\
(\text { atm })\end{array}$ & $\begin{array}{c}\text { Pressão } \\
\text { EVAP-3 } \\
(\text { atm })\end{array}$ & $\begin{array}{c}\text { Pressão } \\
\text { EVAP-4 } \\
(\text { atm })\end{array}$ & $\begin{array}{c}\text { Pressão } \\
\text { EVAP-5 } \\
(\text { atm })\end{array}$ \\
\hline 2,5 & 1,2 & 0,82 & 0,61 & 0,37 & 0,15 \\
\hline
\end{tabular}

\section{RESULTADOS E DISCUSSÃO}

\subsection{Parte Experimental}

A realização do estudo da concentração de ácido no pré-tratamento foi dividida em duas etapas: a etapa de caracterização da biomassa após o pré-tratamento e a etapa de análise do hidrolisado ácido. A Tabela 3 apresenta a caracterização da palha de cana usada como matéria-prima e da biomassa obtida após o tratamento em diferentes concentrações de ácido.

Tabela 3- Caracterização da biomassa após pré-tratamento ácido em diferentes concentrações $\mathrm{de}_{2} \mathrm{SO}_{4}$ (teores expressos como valores médios).

\begin{tabular}{rcccc}
\hline & Matéria-prima & $\mathbf{H}_{2} \mathbf{S O}_{4} \mathbf{~ 1 \%}$ & $\mathbf{H}_{2} \mathbf{S O}_{4} \mathbf{2 , 5} \%$ & $\mathbf{H}_{2} \mathrm{SO}_{4} \mathbf{5 \%}$ \\
\hline Celulose & $41,9 \%$ & $63,9 \%$ & $45,9 \%$ & $47,8 \%$ \\
Hemicelulose & $41,7 \%$ & $15,0 \%$ & $32,7 \%$ & $32,2 \%$ \\
Lignina & $14,6 \%$ & $20,3 \%$ & $20,3 \%$ & $22,9 \%$ \\
\hline
\end{tabular}

Realizou-se um balanço de massa para a determinação da porcentagem de lignina, celulose e hemicelulose removidas pelo pré-tratamento. Os resultados para a porcentagem de remoção de cada componente estão representados no gráfico da Figura 1.

Como o objetivo do pré-tratamento ácido é a remoção da hemicelulose, pode-se constatar que a concentração de $1 \%$ de ácido sulfúrico foi a que apresentou maior porcentagem de remoção. Houve também a remoção de lignina, o que é uma consequência positiva já que a mesma dificulta o acesso das enzimas à celulose. As concentrações de 2,5\% e 5\% apresentaram uma remoção maior, porém, maior perda de celulose, o que não é desejável, pois quanto menos celulose na biomassa, menor será a quantidade de açúcares produzidos na etapa de hidrólise enzimática.

Com essa análise, pode-se notar que as concentrações de 2,5\% e 5\% obtiveram os resultados menos desejáveis, mostrando serem concentrações elevadas de ácido para serem utilizadas em um pré-tratamento com ácido diluído. Além disso, a utilização desta concentração de ácido requer maior volume de base na neutralização do hidrolisado ácido, podendo aumentar a força iônica do meio, o que prejudica a etapa final de fermentação. 


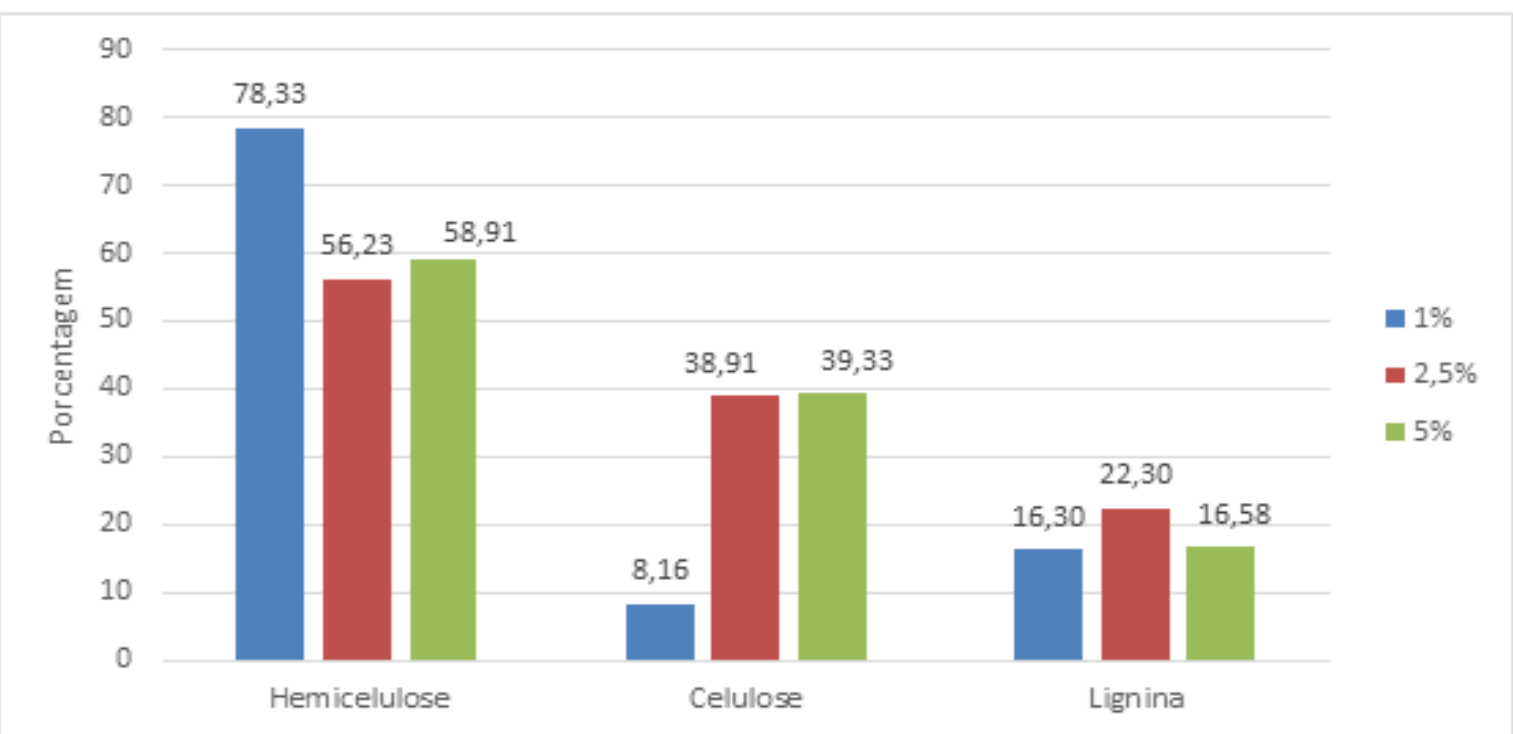

Figura 1 - Remoção percentual das frações lignocelulósicas de acordo com a concentração de ácido utilizada no pré-tratamento.

Também se analisou o hidrolisado ácido com o intuito de quantificar os açúcares. $\mathrm{O}$ melhor hidrolisado é aquele que possuir o menor teor de açúcares, pois significa menor hidrólise da celulose da biomassa que segue para a hidrólise enzimática. A caracterização do hidrolisado ácido foi realizada em duas etapas: quantificação de açúcares (redutores e glicose) como mostra a Tabela 4 e quantificação dos inibidores (HMF e Furfural), na Tabela 5 .

Tabela 4 - Valores de concentração de açúcares no hidrolisado após pré-tratamento ácido.

\begin{tabular}{rccc}
\hline & \multicolumn{3}{c}{ Hidrolisado / Pré-tratamento } \\
\cline { 2 - 4 } & $\mathbf{1 \%} \mathbf{H}_{2} \mathbf{S O}_{4}$ & $\mathbf{2 , 5 0 \%} \mathbf{H}_{\mathbf{2}} \mathbf{S O}_{4}$ & $\mathbf{5 \%} \mathbf{H}_{2} \mathbf{S O}_{4}$ \\
\hline Glicose $(\mathbf{m g} / \mathbf{m L})$ & $0,539 \pm 0,001$ & $0,625 \pm 0,006$ & $0,945 \pm 0,004$ \\
Açúcares redutores $(\mathbf{m g} / \mathbf{m L})$ & $8,391 \pm 0,015$ & $11,036 \pm 0,014$ & $10,697 \pm 0$ \\
\hline
\end{tabular}

Tabela 5- Valores de concentrações dos inibidores após pré-tratamento ácido.

\begin{tabular}{rcc}
\hline \multirow{2}{*}{ Pré-tratamento } & \multicolumn{2}{c}{ Concentração $(\mathbf{m g} / \mathbf{m L})$} \\
\cline { 2 - 3 } & Furfural & HMF \\
\hline $\mathbf{1 \%} \mathbf{H}_{2} \mathbf{S O}_{4}$ & $0,158 \pm 0,0015$ & $0,009 \pm 0,0011$ \\
$\mathbf{2 , 5 0 \%} \mathbf{H}_{2} \mathbf{S O}_{4}$ & $0,205 \pm 2,18 \mathrm{E}-5$ & $0,008 \pm 0,0009$ \\
$\mathbf{5 \%} \mathbf{H}_{2} \mathbf{S O}_{4}$ & $0,470 \pm 0,0128$ & $0,016 \pm 0,0015$ \\
\hline
\end{tabular}

O Furfural e o HMF são tóxicos aos microrganismos responsáveis pela fermentação em qualquer concentração, e a presença da menor quantidade desses inibidores, leva a um menor gasto energético para essa remoção. A influência que esses componentes possuem sobre a fermentação é tão expressiva que a situação ideal é a completa remoção dos mesmos (RASMUSSEN et al., 2014). Observou-se que o tratamento com $1 \%(\mathrm{~m} / \mathrm{m})$ de $\mathrm{H}_{2} \mathrm{SO}_{4}$ apresentou a menor quantidade de açúcares no hidrolisado, e esse resultado colabora para a escolha desta condição. Portanto, concluiu-se que a melhor concentração de ácido a ser 
utilizada é a de $1 \%(\mathrm{~m} / \mathrm{m})$ de ácido sulfúrico, pois há maior remoção de hemicelulose, menor perda de celulose e um hidrolisado com a menor concentração de açúcares e inibidores tóxicos.

Definida a concentração de $\mathrm{H}_{2} \mathrm{SO}_{4}$, estudou-se o tempo de pré-tratamento ácido. $\mathrm{O}$ estudo foi realizado de forma análoga ao estudo da concentração do ácido: a etapa de caracterização da biomassa após o pré-tratamento e a etapa de análise do hidrolisado ácido. A Tabela 6 apresenta a caracterização da biomassa obtida após o tratamento. Com os valores obtidos, realizou-se um balanço de massa para determinar a porcentagem de lignina, celulose e hemicelulose removidas pelo pré-tratamento. Os resultados para a porcentagem de remoção de cada componente estão representados no gráfico da Figura 2.

Tabela 6- Caracterização da biomassa após pré-tratamento ácido com $\mathrm{H}_{2} \mathrm{SO}_{4}$ 1\% (m/m) em diferentes tempos de reação (teores expressos como valores médios).

\begin{tabular}{rccc}
\hline & 15 minutos & 30 minutos & 60 minutos \\
\hline Celulose & $59,4 \%$ & $60,4 \%$ & $63,9 \%$ \\
Hemicelulose & $20,3 \%$ & $18,0 \%$ & $15,0 \%$ \\
Lignina & $19,9 \%$ & $21,4 \%$ & $20,3 \%$ \\
\hline
\end{tabular}

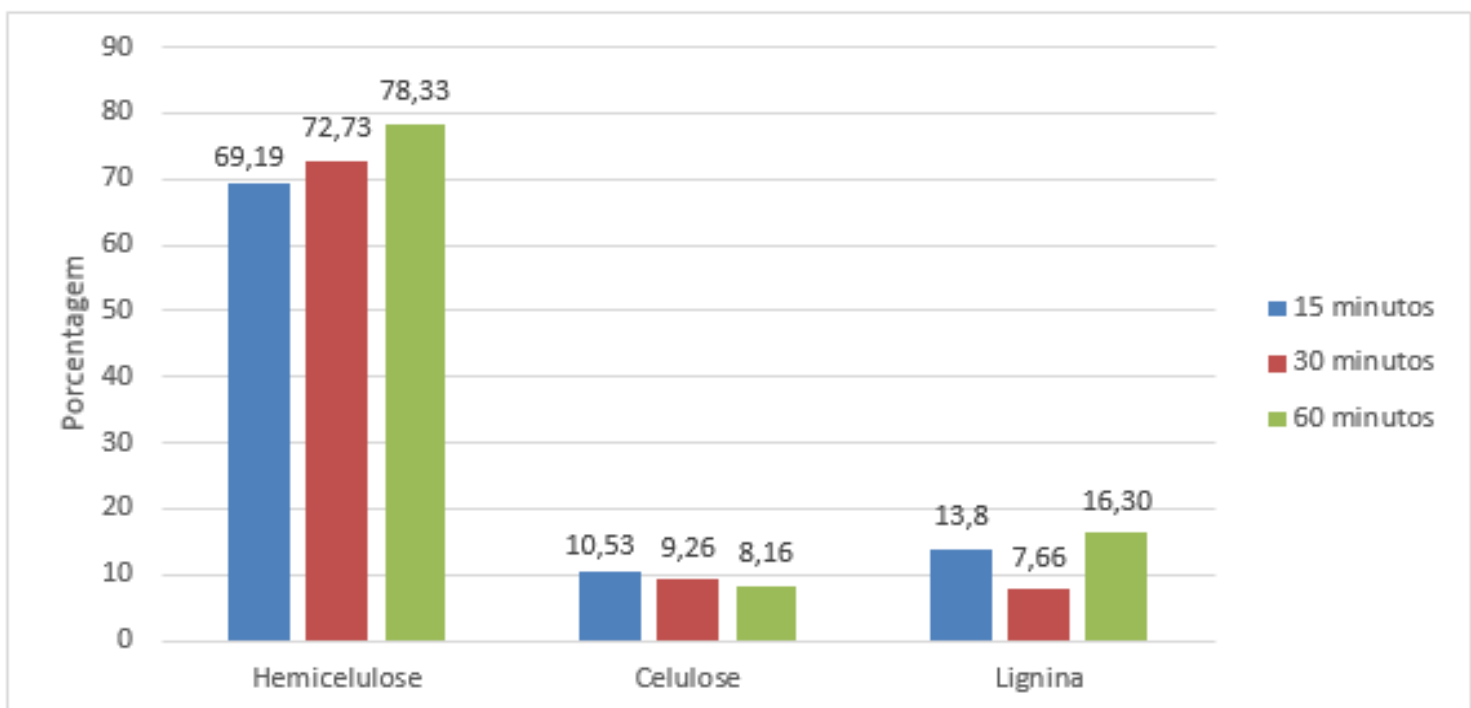

Figura 2 - Remoção percentual das frações lignocelulósicas de acordo com o tempo de reação utilizado no pré-tratamento ácido.

Através da Figura 2 é possível notar uma pequena variação dentre as porcentagens de remoção de celulose. O tempo de 60 minutos apresentou maior remoção de hemicelulose e de lignina, porém, apesar das porcentagens de remoção apresentadas apontarem 60 minutos como a melhor escolha de tempo de reação, deve-se levar em consideração o alto gasto energético que esta opção resultaria. Também se caracterizou o hidrolisado ácido em relação aos teores de açúcares e inibidores. Os dados encontrados com cada teste encontram-se nas Tabelas 7 e 8 , respectivamente. 
Tabela 7 - Valores de concentração de açúcares no hidrolisado após pré-tratamento ácido.

\begin{tabular}{rccc}
\hline & \multicolumn{3}{c}{ Hidrolisado / Pré-tratamento } \\
\cline { 2 - 4 } & $\mathbf{1 5 m i n}$ & 30min & 60min \\
\hline Glicose $(\mathbf{m g} / \mathbf{m L})$ & $0,335 \pm 0,013$ & $0,284 \pm 0,013$ & $0,539 \pm 0,001$ \\
Açúcares redutores $(\mathbf{m g} / \mathbf{m L})$ & $11,396 \pm 0,004$ & $11,501 \pm 0,001$ & $8,391 \pm 0,015$ \\
\hline
\end{tabular}

De acordo com os valores encontrados, observou-se que o hidrolisado para o tempo de 60 minutos apresentou a menor quantidade de açúcares totais. Contudo, desde o princípio, constatou-se que a imprecisão de tempo na autoclave, devido às curvas de aquecimento e resfriamento serem muito lentas (durante este tempo, a amostra fica retida em seu interior reagindo por um período de tempo maior que o necessário), influenciou fortemente nos resultados, comprometendo a decisão sobre o tempo.

Tabela 8 - Valores obtidos para as concentrações dos inibidores.

\begin{tabular}{ccc}
\hline \multirow{2}{*}{ Tempo $(\mathbf{m i n})$} & \multicolumn{2}{c}{ Concentração $(\mathbf{m g} / \mathbf{m L})$} \\
\cline { 2 - 3 } & Furfural & HMF \\
\hline $\mathbf{1 5}$ & $0,032 \pm 0,0025$ & $0,000 \pm 0,0003$ \\
$\mathbf{3 0}$ & $0,070 \pm 0,0022$ & $0,001 \pm 0,0002$ \\
$\mathbf{6 0}$ & $0,158 \pm 0,0015$ & $0,009 \pm 0,0011$ \\
\hline
\end{tabular}

Apesar da forte influência do equipamento no estudo do tempo, observa-se que o hidrolisado que contém a menor concentração de inibidores foi o referente à amostra de 15 minutos, que foi selecionada como a melhor opção para esta etapa, inclusive por conter apenas furfural e ser isento de HMF. Independente desta escolha realizou-se a hidrólise enzimática para os três tempos de reação estudados. Após a hidrolise enzimática, caracterizou-se o hidrolisado enzimático em relação aos teores de açúcares obtidos, que estão apresentados na Tabela 9.

Tabela 9 - Valores obtidos de açúcares após hidrólise enzimática da biomassa.

\begin{tabular}{rccc}
\hline & \multicolumn{3}{c}{ Hidrolisado Enzimático } \\
\cline { 2 - 4 } & $\mathbf{1 5}$ min & $\mathbf{3 0}$ min & $\mathbf{6 0}$ min \\
\hline Glicose $(\mathbf{m g} / \mathbf{m L})$ & $11,096 \pm 0,021$ & $10,550 \pm 0,021$ & $1,453 \pm 0,002$ \\
Açúcares redutores $(\mathbf{m g} / \mathbf{m L})$ & $12,932 \pm 0,001$ & $14,116 \pm 0,008$ & $3,754 \pm 0,001$ \\
\hline
\end{tabular}

É possível observar pela Tabela 9 que o tempo de 60 minutos de pré-tratamento apresentou valores muito baixos de açúcares totais. Isto deve-se, possivelmente, à formação de ácidos húmicos e pseudo-lignina que ocorrem após tratamentos hidrotérmicos e inibem a atividade enzimática de celulase (RASMUSSEN et al., 2014). Os tempos de 15 e 30 minutos apresentaram uma pequena variação, sendo o tempo de 15 minutos o mais adequado devido ao menor gasto energético e menor concentração de inibidores. Finalizou-se a fase experimental com a definição de $1 \%(\mathrm{~m} / \mathrm{m})$ de ácido sulfúrico e 15 minutos de reação como sendo as condições ideais encontradas neste estudo para o pré-tratamento ácido.

\subsection{Processo Proposto}

A Figura 3 apresenta o diagrama de blocos do processo proposto neste estudo. A partir dos dados obtidos experimentalmente, realizou-se um balanço de massa para que os dados 
das correntes fossem alimentados na simulação das etapas de purificação e concentração. As correntes do diagrama foram separadas em primárias $(\mathrm{P})$ e secundárias $(\mathrm{S})$. As correntes primárias relacionam-se com o caminho percorrido pela biomassa e seus derivados, já as secundárias são correntes necessárias para o desenvolvimento de determinadas etapas do processo.

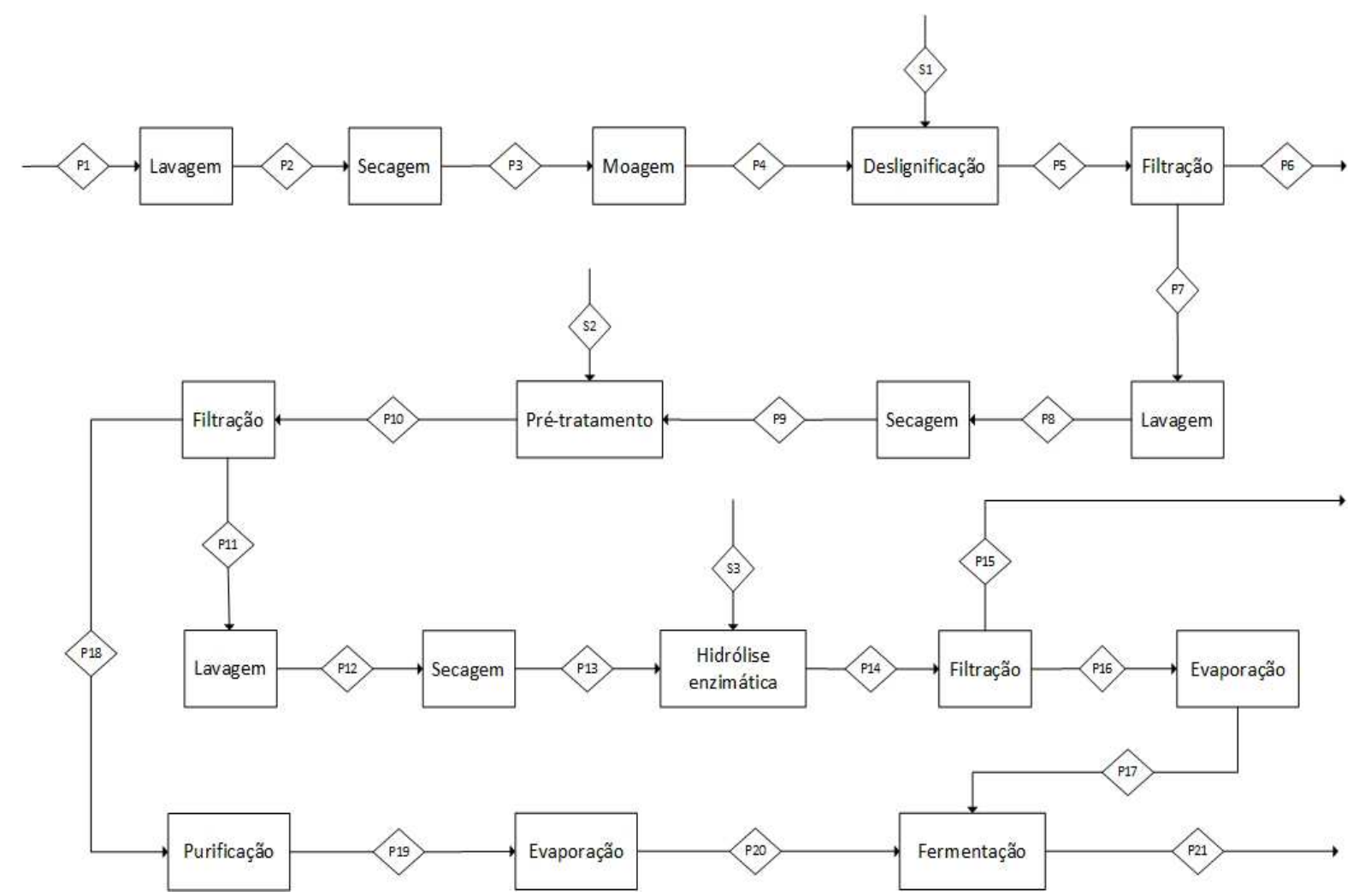

Figura 3 - Diagrama de blocos do processo proposto.

O processo inicia-se com a captação da palha de cana bruta, que passa por lavagem, secagem, moagem e deslignificação com peróxido alcalino. Depois a biomassa deslignificada (P7) é lavada e seca e segue para um pré-tratamento ácido (P9/P10). A fase sólida segue para lavagem (P11), secagem e hidrólise enzimática, a qual após filtração, gera a corrente líquida de hidrolisado (P16- corrente C6), que segue para evaporação, para gerar o mosto de fermentação (P17). A corrente líquida do pré-tratamento (P18- corrente C5) segue para a purificação, para separação do furfural, e posterior evaporação, para concentração dos açúcares, para ser incorporada no mosto fermentativo (P20).

Determinaram-se os valores de todas as correntes do processo, para alimentar a simulação da remoção dos inibidores tóxicos e concentração das correntes que contem açúcar. Adotou-se como base de cálculo a entrada no processo de 1 ton/dia de palha de cana bruta e obteve-se ao final uma vazão mássica de 18373,92 kg/dia para corrente C5 e $14429,85 \mathrm{~kg} /$ dia para corrente C6. 


\subsection{Simulação}

A simulação foi dividida em quatro etapas: definição do modelo termodinâmico, purificação da corrente C5, concentração da corrente C5 e concentração da corrente C6. Na definição do modelo termodinâmico, observou-se que a mistura água e furfural apresentou um ponto de azeótropo. Horsley (1973) verificou que a mistura água-furfural a $600 \mathrm{mmHg}$ apresenta ponto azeótropo em $91,3{ }^{\circ} \mathrm{C}$ e uma fração mássica de $65 \%$ de água e, portanto, é uma mistura que se desvia da idealidade. Além disto, contém um componente relativamente polar e está a uma pressão baixa, assim foi utilizado um modelo termodinâmico de coeficiente de atividade. O modelo NRTL (non-random two liquid) foi selecionado.

Purificação e Concentração da Corrente C5: Para promover a purificação e concentração da corrente C5 estudaram-se três situações distintas: a utilização somente do flash, a utilização de uma coluna de destilação e, a aplicação de uma coluna de destilação em conjunto com evaporadores de múltiplos efeitos com cinco estágios. Durante a análise da remoção e concentração de xilose da corrente C5 através da coluna de destilação em conjunto com evaporadores múltiplos optou-se por utilizar somente evaporadores de múltiplos efeitos. Vale ressaltar que, no presente trabalho, estipulou-se uma remoção desejada de furfural ao ponto do software indicar traços do mesmo e concentração da corrente final entre $14 \%$ a $20 \%$ $(\mathrm{m} / \mathrm{m})$ de açúcares (faixa mais indicada para corrente que segue para fermentação).

A aplicação do flash iniciou-se com temperatura de operação de $100,8^{\circ} \mathrm{C}$, tal situação demonstrou-se ineficaz pois gerou baixa remoção de furfural. Aumentou-se a temperatura de operação para $170^{\circ} \mathrm{C}$ porém constatou-se que a remoção não é completa mesmo em temperaturas mais elevadas. Há também a remoção elevada de água e concentração exagerada de açúcares (fração mássica 0,983 de xilose). Esses resultados e o alto gasto energético (cerca de $3,37 \mathrm{~kW} / \mathrm{kg}$ de xilose formada para a temperatura de $170^{\circ} \mathrm{C}$ ) impossibilitam a sua viabilidade para o processo estudado.

O segundo processo estudado empregou uma coluna de destilação, onde, primeiramente fixou-se o número de pratos em 10 e variou-se a vazão de destilado, como mostra a Figura 4. A avaliação da vazão de destilado mais adequada para obter a concentração de açúcares na corrente C5 na faixa desejada foi realizada através da análise de sensibilidade. Avaliou-se qual a melhor vazão mássica de destilado, a qual não apresentou uma variação expressiva entre a faixa de concentração desejada, assim escolheu-se a vazão de destilado (16878,2 kg/dia), referente a concentração de $14 \%$ de açúcares, para dar continuidade à análise do processo. A remoção de furfural utilizando uma vazão de destilado igual a 16878,2 kg/dia mostrou-se eficiente, uma vez que apresentou apenas traços de furfural na corrente final. $\mathrm{O}$ diâmetro do prato encontrado foi de aproximadamente $54,14 \mathrm{~cm}$, valor aceitável para a construção de uma coluna de pratos. A partir desta vazão de destilado, variou-se o número de pratos e determinou-se 8 pratos como o ideal. Porém, a purificação ainda permaneceu com alto gasto energético $(4,21 \mathrm{~kW} / \mathrm{kg}$ de xilose formada), o que inviabiliza a aplicação deste equipamento, e portanto, tornou-se necessário estudar uma integração energética, afim de reduzir o elevado gasto energético. 


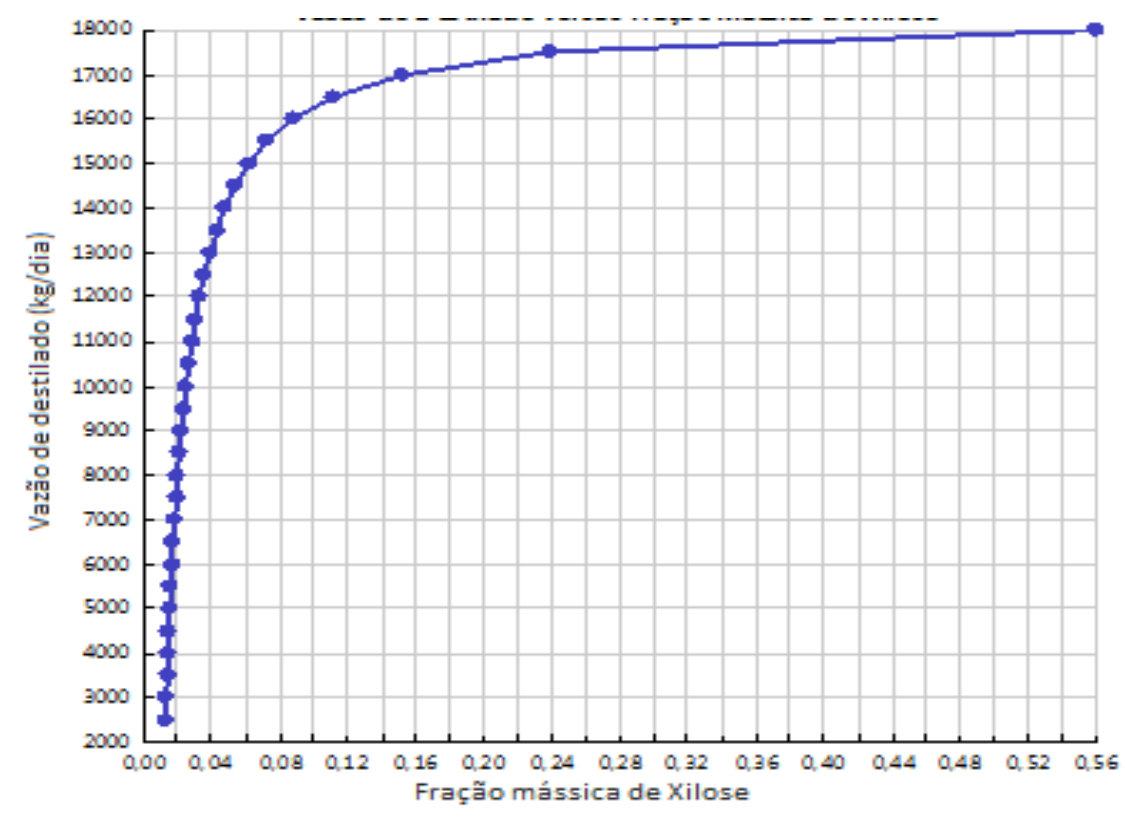

Figura 4 - Vazão de destilado versus fração mássica de xilose.

A última opção estudada refere-se à aplicação de uma coluna de recheio integrada a evaporadores múltiplos com cinco efeitos. A primeira parte da simulação deste processo ocorreu fixando a vazão de destilado em $2500 \mathrm{~kg} /$ dia e a concentração de açúcares da corrente final (saída do evaporador) em $18 \%$. Foi estudado o número de pratos que melhor atendesse o processo, para posteriormente variar a vazão de destilado e, por fim, a concentração de açúcares finais. Na simulação de uma coluna com 10 pratos, verificou-se que o diâmetro dos pratos obtidos para esta simulação encontrou-se abaixo do mínimo usual de $50 \mathrm{~cm}$ para fabricação dos pratos utilizados. Desta maneira, o tipo de coluna mudou de coluna de pratos para coluna de recheio (este tipo de coluna não requer um tamanho mínimo dos estágios presentes nela). Determinaram-se 8 estágios como a situação mais adequada para a remoção completa do furfural. O próximo passo foi variar a vazão de destilado, obtendo o valor de $2040 \mathrm{~kg} / \mathrm{dia}$ como o ideal para a remoção completa do furfural.

Definida as condições de operação da coluna de destilação (número de efeitos e vazão de destilado) seguiu-se para o estudo do efeito da concentração da corrente C5. As condições que se mantiveram fixas foram as pressões de cada estágio do evaporador e a vazão de alimentação do primeiro evaporador proveniente da etapa de purificação. O estudo foi realizado aplicando diferentes concentrações finais para a corrente C5, a qual segue para a fermentação e deve ter valores entre $14 \%$ a $20 \%$ de açúcares. Com a aplicação do conjunto de evaporadores múltiplos (5 estágios) determinou-se a concentração mais final da corrente final C5, encontrando um valor de $20 \%$ de açúcares e traços de furfural, com consumo energético de $0,85 \mathrm{~kW} / \mathrm{kg}$ de xilose formada de energia, um valor aceitável.

Ao longo do estudo da purificação e concentração da corrente C5 através da coluna integrada a evaporadores múltiplos observou-se que os evaporadores apresentaram papel determinante na remoção do furfural e assim tornou-se relevante o estudo desta operação através da aplicação dos evaporadores isoladamente. Após a análise da capacidade de remoção do inibidor gerada pelos evaporadores, constatou-se que os mesmos, isoladamente, não supriram os objetivos estabelecidos, logo não representaram uma opção viável. Após 
todo o estudo realizado, definiu-se que a operação mais adequada para a corrente C5 corresponde a aplicação da coluna de recheio integrada a evaporadores múltiplos com cinco efeitos.

Concentração da Corrente C6: Para realizar a concentração da corrente C6 estudou-se a utilização de evaporadores múltiplos com quatro estágios. Optou-se por variar a concentração da corrente final entre $14 \%$ a $20 \%$ de açúcares, para analisar qual concentração requer menor gasto energético. Pôde-se notar uma baixa variação em relação ao gasto energético entre as concentrações estudadas entre $0,33 \mathrm{~kW} / \mathrm{kg}$ de glicose formada e $0,34 \mathrm{~kW} / \mathrm{kg}$ de glicose formada, logo a definição da concentração mais adequada depende de fatores externos aos abordados neste trabalho, como a etapa de fermentação.

\section{CONCLUSÃO}

De acordo com os dados obtidos experimentalmente, concluiu-se que a condição mais adequada para o pré-tratamento ácido de palha de cana deslignificada, ocorreu com concentração de ácido sulfúrico de $1 \%(\mathrm{~m} / \mathrm{m})$ e tempo de reação de 15 minutos, dentre outras condições fixadas. Nesta condição atingiu-se uma remoção de cerca de $70 \%$ da hemicelulose. O hidrolisado ácido (corrente C5) apresentou uma concentração de furfural de $0,03 \mathrm{mg} / \mathrm{mL}$ e HMF não detectável, e uma concentração de açúcares redutores totais de 11,4 g/L, que foram representados na simulação como xilose. $O$ teor de glicose nesta fase foi menor que $0,5 \mathrm{~g} / \mathrm{L}$. A hidrólise enzimática foi aplicada na biomassa proveniente do pré-tratamento ácido e o hidrolisado enzimático (corrente C6) obteve uma concentração de açúcares redutores totais de $13 \mathrm{~g} / \mathrm{L}$ e glicose de $11 \mathrm{~g} / \mathrm{L}$.

Para a simulação, realizou-se um balanço material de todas as correntes e a construção do diagrama de blocos do processo. Com estas correntes definidas, realizou-se o estudo da purificação e concentração da corrente C5 e concentração da corrente C6. Dentre os processos estudados, o que melhor se adequou para remoção completa de furfural e concentração dos açúcares da corrente C5 correspondeu a uma coluna de recheio (8 pratos e $2040 \mathrm{~kg} /$ dia de vazão de destilado) integrada a evaporadores múltiplos com cinco efeitos (concentração de $20 \%$ de açúcares). A concentração da corrente C6 utilizou evaporadores de múltiplos efeitos com quatro estágios e não apresentou grande variação no gasto energético para concentrar a corrente entre $14 \%$ e $20 \%$ de açúcares.

\section{AGRADECIMENTOS}

Ao Centro Universitário FEI pelo suporte para o desenvolvimento do trabalho.

\section{REFERÊNCIAS}

ADEN, A. et al. Lignocellulosic Biomass to ethanol process design and economics utilizing co-current dilute acid prehydrolysis and enzymatic hydrolysis for corn stover. NREL/TP-510-32438. Golden, CO: NREL-National Renewable Energy Laboratory, June 2002.

AZZAM, A. M. Pretreatment of cane bagasse with hydrogen peroxide for enzymatic hydrolysis of cellulose and ethanol fermentation. Journal of Environmental Science and Health B, p.421-423,1989 (DOI: 10.1080/03601238909372658). 
GHOSE, T. K. Measurement of cellulase activities. Pure and Applied Chemistry. Grã Bretanha, International Union of Pure and Applied Chemistry, v. 59, n. 2, p. 257 - 268, 1987. Disponível em: < https://www.iupac.org/publications/pac2007/1987/pdf/5902x0257.pdf>. Acesso em: 25 abr. 2016.

GONÇALVES, C. Aplicação de agentes oxidantes no pré-tratamento do bagaço de canade-açúcar e sua influência na sacarificação da celulose. 2009. 74f. Dissertação (Mestrado) - Engenharia de Processos Químicos e Bioquímicos, Centro Universitário do Instituto Mauá de Tecnologia, São Caetano do Sul, 2009.

GROSSI, E. Produção de etanol de segunda geração a partir de um derivado de celulose. 2015. 75f. Dissertação (Mestrado) - Curso de Tecnologias Química e Biológica, Instituto de Química da Universidade de Brasília, Brasília-DF, 2015.

GUHA, S.K.; KOBAYASHI, H.; FUKUOKA, A. Conversion of Cellulose to Sugars. In: CROCKER, M. (Ed.). Thermochemical conversion of biomass to liquid fuels and chemicals. 1. ed. Cambridge: RSC Publishing, cap. 13, p. 344-364, 2010.

HORSLEY, L. H. Azeotropic Data, v. 3, Washington: American Chemical Society, 1973.

LIMA. U. A.; AQUARONE, E.; BORZANI, W.; SCHIMIDELL, W. Biotecnologia Industrial: processos fermentativos e enzimáticos. São Paulo: Edgard Blücher, 2001. V. 3.

MILLER, G. L. Use of dinitrosalicylic acid reagent for determination of reducing sugar. Analytical Chemistry, p.426-428, 1959. Disponível em: <http://pubs.acs.org/doi/abs/10.1021/ac60147a030>. Acesso em 27 jul. 2015.

MORAIS, J.P.S.; ROSA, M.F.; MARCONCINI, J.M. Procedimentos para análise lignocelulósica. Campina Grande, PB: Embrapa Algodão, 2010. p. 54. (Embrapa Algodão. Documentos, 236).

NOVACANA. A produção de cana-de-açúcar no Brasil (e no mundo). [S.I.]: 2013. Disponível em: <https://www.novacana.com/cana/producao-cana-de-acucar-brasil-emundo/>. Acesso em: 15 mar. 2016.

OLIVEIRA, F. Avaliação de diferentes pré-tratamentos e deslignificação alcalina na sacarificação da celulose de palha de cana. 2010. 99f. Dissertação (Mestrado) Biotecnologia Industrial, Escola de Engenharia de Lorena, Lorena, 2010.

RAIZEN. Tecnologia em energia renovável. [S.I.]: 2014. Disponível em: $<$ http://www.raizen.com/energia-do-futuro-tecnologia-em-energia-renovavel/etanol-desegunda-geracao $>$. Acesso em: 09 mar. 2016.

RAMOS, L. P. The chemistry involved in the steam treatment of lignocellulosic materials. Quim. Nova, v.26, p. 863-871, 2003.

RASMUSSEN, H.; SØRENSEN, H.R.; MEYER, A.S. Formation of degradation compounds from lignocellulosic biomass in the biorefinery: sugar reaction mechanisms. Carbohydrate Research, n. 385, 2014. 45-57.

SANTOS, F.A.; QUEIRÓZ, J.H.; COLODETTE, J.L.; FERNANDES, S.A.; GUIMARÃES, V.M.; T. REZENDE, S.T. Potencial da palha de cana-de-açúcar para produção de etanol. Química Nova, v. 35, n. 5, p. 1004-1010, 13 jan 2012. Disponível em: < http://quimicanova.sbq.org.br/imagebank/pdf/Vol35No5_1004_24-RV11835_cor.pdf>. Acesso em: 08 maio 2016.

SILVA, V. Estudo de pré-tratamento e sacarificação enzimática de resíduos agroindustriais como etapas no processo de obtenção de etanol celulósico. 2009. 116f. Dissertação (Mestrado) - Biotecnologia Industrial, Escola de Engenharia de Lorena, Lorena, 2009. 
SJÖSTRÖM, E. Wood Chemistry: fundamentals and applications. 2. ed. São Diego: Academic Press, Inc., 1993.

TAPPI. T 222 om-02. Acid-insoluble lignin in wood na pulp. Georgia, 2002, p. 5.

ZAUTSEN, R. Fermentação alcoólica e extração líquido-líquido simultânea de etanol e inibidores provenientes de caldo hidrolítico de biomassa lignocelulósica. 2011. 194 f. Tese (Doutorado) - Curso de Engenharia de Alimentos, Faculdade de Engenharia de Alimentos da Unicamp, Campinas, 2011.

\title{
STUDY OF THE REMOVAL OF FERMENTATION INHIBITORS AFTER ACID AND ENZYMATIC TREATMENT OF CANE STRAW
}

\author{
A. C. LUCARINI ${ }^{1, *}$, N. L. FERREIRA ${ }^{1}$, C. D. SOUZA ${ }^{1}$, F. P. L. FRANCISCO ${ }^{1}$, \\ I. R. FONSECA ${ }^{1}$, L. G. ROSSI ${ }^{1}$ e V. M. FERREIRA ${ }^{1}$ \\ ${ }^{1}$ FEI University, Department of Chemical Engineering \\ *E-mail: lucarini@fei.edu.br
}

\begin{abstract}
It was studied the removal of toxic inhibitors produced during dilute-acid pretreatment of lignocellulosic biomass. Different sulfuric acid concentrations $(1 \%, 2.5 \%$ and 5\%) and reaction times $(15,30$ and 60 minutes) were analyzed for the pretreatment process, and, $1 \% \mathrm{w} / \mathrm{w} \mathrm{H}_{2} \mathrm{SO}_{4}$ and 15-minute reaction time have proven to be the most proper condition. With the experimental data, purification and concentration operations were simulated. For C5 stream (xylose, furfural and water) three different unit operations have been explored: a flash drum, a distillation column and a distillation column followed by multiple-effect evaporators. The distillation column with five multiple-effect evaporator system achieved the best energy efficiency $(0,85 \mathrm{~kW} / \mathrm{kg}$ xylose $)$ and removal of furfural. For C6 stream (glucose and water), a four multiple-effect evaporator system simulated showed that the energy requirements not change significantly within the range of sugar concentration used $(14 \%$ to $20 \%)$.
\end{abstract}

KEYWORDS: Ethanol; Furfural; Lignocellulosics; Acid pretreatment; Biomass. 